\title{
Experimental immunization of mice with a recombinant bovine enterovirus vaccine expressing BVDV E0 protein elicits a long- lasting serologic response
}

Xiao Ren ${ }^{1+}$, Shan Zhang ${ }^{1 \dagger}$, Xintao Gao ${ }^{2}$, Xiaoyu Guo ${ }^{1}$, Ting Xin ${ }^{1}$, Hongfei Zhu' ${ }^{1}$ Hong Jia ${ }^{1 *}$ and Shaohua Hou ${ }^{1 *}$

\begin{abstract}
Background: Bovine viral diarrhea virus (BVDV) is a cause of substantial economic loss to the cattle industry worldwide, and there are currently no effective treatment or preventive measures. Bovine enterovirus (BEV) has a broad host range with low virulence and is a good candidate as a viral vaccine vector. In this study, we explored new insertion sites for the expression of exogenous genes in BEV, and developed a recombinant infectious cDNA clone for BEV BJ101 strain expressing BVDV E0 protein.

Methods: A recognition site for the viral proteinase $3 C^{\text {pro }}$ was inserted in the GpBSK-BEV plasmid at the 2C/3A junction by overlapping PCR. Subsequently, the optimized full-length BVDV E0 gene was inserted to obtain the recombinant infectious plasmid GpBSK-BEV-EO. The rescued recombinant virus was obtained by transfection with linearized plasmid. Expression of BVDV EO in the recombinant virus was confirmed by PCR, western blotting, and immunofluorescence analysis, and the genetic stability was tested in MDBK cells over 10 passages. We further tested the ability of the recombinant virus to induce an antibody response in mice infected with BVDV and immunized them with the recombinant virus and parental strain.
\end{abstract}

Results: The rescued recombinant virus rBEV-EO was identified and confirmed by western blot and indirect immunofluorescence. The sequencing results showed that the recombinant virus remained stable for 10 passages without genetic changes. There was also no significant difference in growth dynamics and plaque morphology between the recombinant virus and parental virus. Mice infected with both recombinant and parental viruses produced antibodies against BEV VP1, while the recombinant virus also induced antibodies against BVDV E0.

Conclusion: A new insertion site in the BEV vector can be used for the prevention and control of both BEV and BVDV, providing a useful tool for future research on the development of viral vector vaccines.

Keywords: Bovine enterovirus, Bovine viral diarrhea virus, E0 gene, 2C/3A junction, Viral vector

\footnotetext{
*Correspondence: jiahong@caas.cn; houshaohua@caas.cn

${ }^{+}$Xiao Ren and Shan Zhang contributed equally to this work.

'Institute of Animal Sciences, Chinese Academy of Agricultural Sciences, No.

2, Yuan Ming Yuan West Road Haidian District, Beijing 100193, China

Full list of author information is available at the end of the article
}

C C The Author(s). 2020 Open Access This article is licensed under a Creative Commons Attribution 4.0 International License, which permits use, sharing, adaptation, distribution and reproduction in any medium or format, as long as you give appropriate credit to the original author(s) and the source, provide a link to the Creative Commons licence, and indicate if changes were made. The images or other third party material in this article are included in the article's Creative Commons licence, unless indicated otherwise in a credit line to the material. If material is not included in the article's Creative Commons licence and your intended use is not permitted by statutory regulation or exceeds the permitted use, you will need to obtain permission directly from the copyright holder. To view a copy of this licence, visit http://creativecommons.org/licenses/by/4.0/ The Creative Commons Public Domain Dedication waiver (http://creativecommons.org/publicdomain/zero/1.0/) applies to the data made available in this article, unless otherwise stated in a credit line to the data. 


\section{Background}

Bovine enterovirus (BEV) was first reported in 1957 and has been prevalent in major cattle breeding countries and regions worldwide, including the United States, Canada, the United Kingdom, Germany, Poland, Pakistan, and China [1-3]. Infection with BEV typically manifests as subclinical symptoms, but can cause diarrhea and respiratory diseases in certain cases [4]. BEV uses a wide range of animals as hosts, including bovine [5], moose [6], sheep [7], opossums [8], and dolphins [9]. In certain cases, human blood samples have also tested positive for the virus [10]. According to the latest classification of viruses, bovine enterovirus is divided into groups EV-E and EV-F, with EV-E four subtypes (EVE1-E4) and EV-F divided into six subtypes (EV-F1-F6) [11]. BEV is a member of the genus Enterovirus in the family Picornavirus. The virion is spherical, icosahedral, non-encapsulated, and has a diameter of $25-30 \mathrm{~nm}$. The viral genome is a non-segmented single-stranded positivestranded RNA with a total length of about $7.5 \mathrm{~kb}$. It can directly translate a polyprotein as mRNA and undergoes a series of degradation steps to produce four structural egg proteins (VP1-VP4) and seven non-structural proteins $\left(2 \mathrm{~A}^{\text {pro }}, 2 \mathrm{~B}, 2 \mathrm{C}, 3 \mathrm{~A}, 3 \mathrm{~B}, 3 \mathrm{C}^{\text {pro }}\right.$, and $\left.3 \mathrm{D}\right)$, among which the viral protease $3 C^{\text {pro }}$ recognizes and cleaves a characteristic amino acid sequence (ALPQG) within exposed and flexible structural domains $[12,13]$.

$\mathrm{BEV}$ is generally considered to be non-virulent or of low virulence, not highly pathogenic, resistant to acidic environments, and can infect animals through the intestinal tract, making it a good candidate for a vaccine vector. Despite substantial progress in the development of recombinant and chimeric human enteroviruses such as poliovirus and EV-71 virus [14], relatively little research has been done on BEV in this regard. Chang et al. [15] inserted the foot-and-mouth disease virus (FMDV) type O-conserved neutralizing epitope 8E8 into the VP1 B-C or D-E loops of BEV (BHM26 strain). Chu et al. [16] inserted the main antigen neutralization epitope (residues 141-160) of the FMDV (vaccine strain O1/Manisa/Turkey/69) VP1 gene into the junction of VP1/ $2 \mathrm{~A}$ of BEV (LC-R4 strain). Liu et al. [17] constructed a recombinant infectious $\mathrm{BEV}$ clone by insertion of the epitope of influenza virus hemagglutinin (HA) into the 3A or VP1 gene of BEV (HY12 strain), respectively. These studies indicated that the biological characteristics of recombinant $\mathrm{BEV}$ are similar to those of the parental virus, and experimental infection animal models could produce immune responses to the exogenous genes. However, these studies only explored some of the circulating strains and potential insertion sites, and many other strains and other highly effective potential insertion sites remain to be investigated.
Bovine viral diarrhea virus (BVDV), a single-stranded positive-strand RNA virus belonging to the family Flaviviridae and the genius Pestivirus, is the cause of bovine viral diarrhea (BVD). BVD is a complex disease with various clinical manifestations and is considered one of the main threats to the cattle industry worldwide. BVDV not only infects cattle but also infects sheep, goats, pigs, deer, and other ruminants with a wide host range [18]. Since there is currently no specific treatment for BVD, it is particularly important to find new measures to prevent its occurrence and transmission. The BVDV E0 gene is highly conserved in the BVDV genome and has a neutralization epitope [19], which can generate the production of a neutralization antibody to neutralize BVDV. Therefore, we explored the possibility of BVDV E0 as a candidate antigen for the genetic engineering of a subunit vaccine using BEV.

In this study, we used the BEV BJ101 strain as a viral vector to express exogenous genes by inserting the BVDV E0 gene between the genes encoding the nonstructural proteins $2 \mathrm{C}$ and $3 \mathrm{~A}$. We compared the replication, infection, and biological characteristics of the rescued recombinant virus after insertion to those of the parental virus, and evaluated the expression of E0 protein and its ability to induce an immune response in vivo.

\section{Methods}

RNA extraction and cDNA synthesis

Viral RNA was extracted from Madin-Darby bovine kidney (MDBK) cells (provided by Hebei Agricultural University) infected with the BEV BJ101 strain (maintained in our laboratory) using an RNA extraction kit (AXYGEN, Hangzhou, China). The first-strand cDNA of the virus was synthesized with the PrimeScript ${ }^{\mathrm{TM}}$ II 1 st Strand cDNA Synthesis kit (Takara, Beijing, China).

\section{Optimization and synthesis of BVDV E0}

Mammalian codon optimization was carried out on the gene sequence of BVDV E0 (GenBank: EU709763.1) and the optimized sequence is shown in Additional File 1. A Not $\mathrm{I}$ enzyme cleavage site was added to the $5^{\prime}$ end and an $\mathrm{XbaI}$ enzyme cleavage site was added to the $3^{\prime}$ end. The whole gene sequence was connected to the pUC-57 plasmid vector and named pUC57-E0.

\section{Construction of infectious cDNA clones of the recombinant virus}

In accordance with the strategy schematically outlined in Fig. 1, a full-length BEV BJ101 infectious cDNA clone harboring the exogenous gene BVDV E0 was generated by inserting the optimized nucleotide sequence of BVDV $\mathrm{E} 0$ at the $2 \mathrm{C} / 3 \mathrm{~A}$ junction of the virus. 


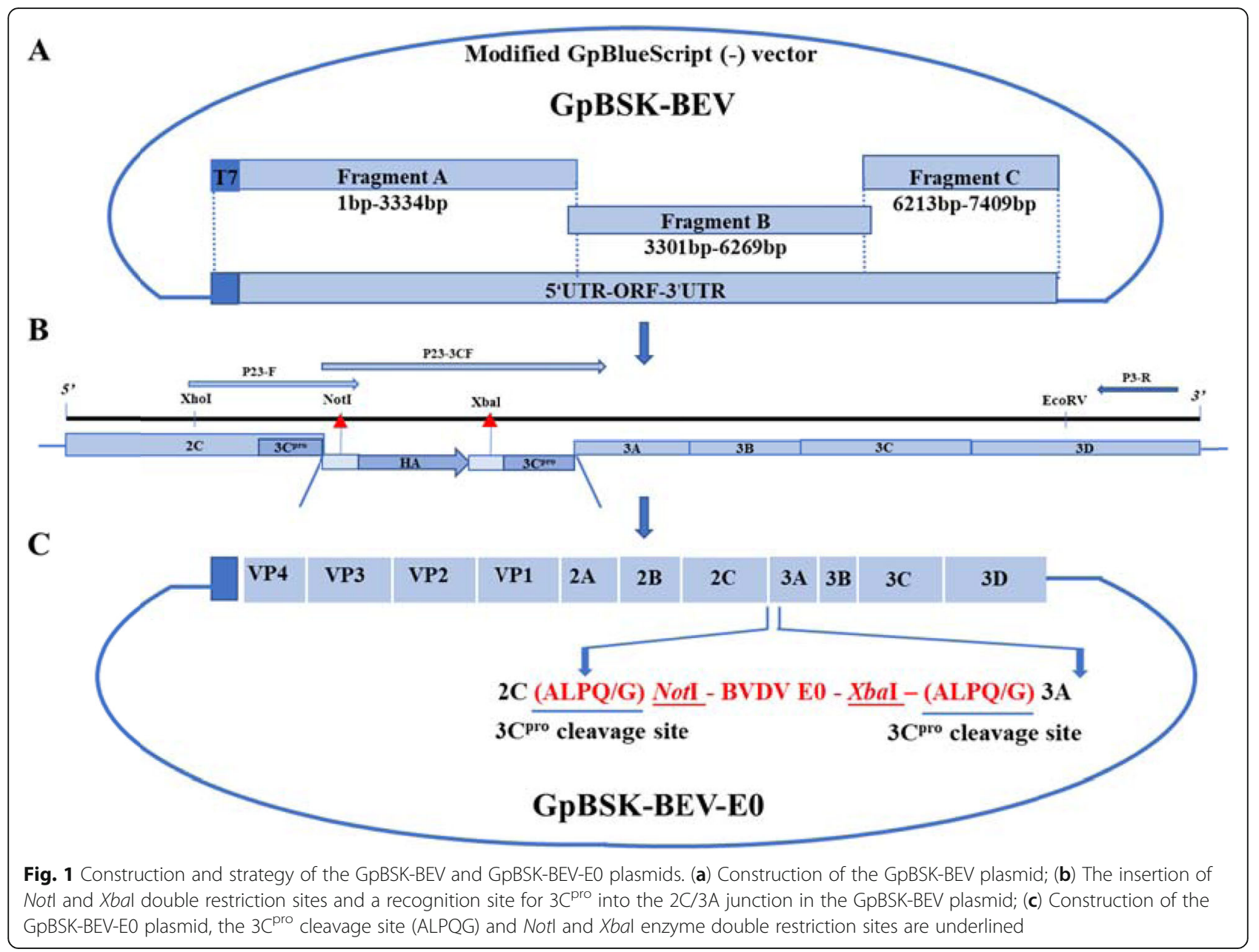

The synthesized cDNA was used as a template for subsequent polymerase chain reaction (PCR) amplification. The genome sequence of BEV BJ101strain (GenBank: MG650158.1) was divided into three fragments, fragment $\mathrm{A}, \mathrm{B}$ and $\mathrm{C}$, containing nucleotides 1-3334, 3301-6269, and 6213-7409, respectively, for amplification. Three pairs of specific primers (A-F/R, B$\mathrm{F} / \mathrm{R}, \mathrm{C}-\mathrm{F} / \mathrm{R}$ ) were designed to amplify the three fragments, and cloned into the modified GpBlueScript (-) vector (stored in our laboratory; see Additional File 2) by homologous recombination to generate the fulllength cDNA clone of GpBSK-BEV (Table 1).
The NotI and $X b a \mathrm{I}$ double restriction sites and a recognition site for $3 C^{\text {pro }}$ were inserted at the $2 C / 3 \mathrm{~A}$ junction in the GpBSK-BEV plasmid by overlapping PCR (Table 2). In brief, the GpBSK-BEV plasmid was used as the first template, P23-3CF and P3-R were the primers, and PCR was performed in accordance with PrimeSTAR $^{\circ}$ HS (Premix) specifications (Takara, Beijing, China). The amplified product served as the subsequent template using the primers $\mathrm{P} 23-\mathrm{F}$ and $\mathrm{P} 3-\mathrm{R}$ for the second PCR. The obtained product and GpBSK-BEV plasmid were then subjected to double enzyme digestion using the XhoI and EcoRV restriction enzymes (Takara,

Table 1 Primers for the construction of full-length cDNA clone of BEV

\begin{tabular}{|c|c|c|}
\hline Primer name & Primer sequence ( $5^{\prime}$ to $\left.3^{\prime}\right)$ & Product size $(\mathrm{bp})$ \\
\hline BEV-AF & $\begin{array}{l}\text { GTAAAACGACGGCCAGTGAATTGGTCGACTAATACGACTCACTATAGGGTTAAAACAGCCTGGGGGTTG } \\
\end{array}$ & 3383 \\
\hline BEV-AR & GGGCCCAATGTGGTCAGGGAGGATCGATCGGTGCAGATCTTATCGGTG & \\
\hline BEV-BF & GCACCGATCGATCCTCCCTGACCACATTGGGCCCATTTGGAC & 2969 \\
\hline BEV-BR & GCCTTCAGTACCATAAATGGCATCCTCCATGGATATCGGCCTAGG & \\
\hline BEV-CF & CTAAATATTGATCCTAGGCCGATATCCATGGAGGATGCC & 1249 \\
\hline BEV-CR & CTCGAAATTAACCCTCACTAAAGGGAACGAATTCTTTाTाTाTाTाTाTTACACCCCATCCGGTG & \\
\hline
\end{tabular}


Table 2 Primers for overlapping PCR

\begin{tabular}{llc}
\hline Primer name & Primer sequence (5' to 3') & Product size (bp) \\
\hline P23-F & GCAATAGGCGTTATAACATTGGGAACGTCCTCGAGGCACTCTTCCAGGGCGGCCGCTACCCATACGAC & 1317 \\
P23-3CF & GGCGGCCGCTACCCATACGACGTCCCAGACTACGCTTCTAGAGCACTCTTCCAGGGCCCAGTTGGCTACAAACCCCTC & 1270 \\
P3-R & CCAGGGCCTCCAAGCCTTCAGTAC & \\
\hline
\end{tabular}

Note: Notl (GCGGCCGC) and Xbal (TCTAGA) enzyme double restriction sites are italic, bold and underlined

Beijing, China) present in the original plasmid. An HA tag was added between the NotI and XbaI restriction sites to prevent the proximity of the two enzyme cleavage sites from affecting the efficiency of double enzyme cleavage. Finally, the GpBSK-BEV plasmid containing Not $\mathrm{I}$ and XbaI enzyme cleavage sites was obtained through a T4 ligase (Takara, Beijing, China) connection.

The pUC57-E0 and GpBSK-BEV plasmids were digested with NotI and XbaI enzymes (Takara, Beijing, China), respectively. Subsequently, T4 ligase was used for overnight ligation at $16^{\circ} \mathrm{C}$, and the product was transferred into the competent cells of Escherichia coli JM109 (Sangon, Shanghai, China). Positive clones were sent to Genewiz (Suzhou, China) for sequencing, and the correct plasmid was named GpBSK-BEV-E0.

\section{Linearization of the recombinant plasmid}

The recombinant plasmid GPBSK-BEV-E0 was linearized by the EcoRI restriction enzyme (Takara, Beijing, China). The enzyme digestion system comprised $10 \mu \mathrm{g}$ recombinant plasmid, $40 \mu \mathrm{L}$ of $5 \times$ CutSmart buffer, $8 \mu \mathrm{L}$ EcoR I-HF, and RNase Free $\mathrm{ddH}_{2} \mathrm{O}$ up to $200 \mu \mathrm{L}$. Enzyme digestion was performed at $37^{\circ} \mathrm{C}$ for $3 \mathrm{~h}$, and the restriction enzyme was inactivated at $65{ }^{\circ} \mathrm{C}$ for $20 \mathrm{~min}$. Linear plasmids were recovered from the agarose gel and purified by ethanol precipitation.

\section{Transfection and rescue of the recombinant virus}

Linearized GpBSK-BEV-E0 was transfected in BSR-T7 cells (provided by Hebei Agricultural University) using a transfection kit (Polyplus, NA, USA) according to the manufacturer's instructions. In brief, BSR-T7 cells were inoculated into a six-well plate until covering $80 \%$ of the bottom of the wells, and then washed with phosphate buffered saline (PBS). Two milliliters of Dulbecco's modified Eagle's medium (DMEM; Life Technologies, CA, USA) containing $2 \%$ fetal bovine serum (FBS; Sigma-Aldrich, St. Louis, MO, USA) was added to each well, and $200 \mu \mathrm{L}$ of jetPRIME buffer and $2 \mu \mathrm{g}$ DNA were added to the sterilized $1.5-\mathrm{mL}$ tube and mixed gently. Subsequently, another $4 \mu \mathrm{L}$ of jetPRIME was added, mixed gently, centrifuged at low speed for $10 \mathrm{~s}$, and left to react at room temperature for $10 \mathrm{~min}$. The mixture was then added to a six-well plate and cultured in the cell incubator at $37^{\circ} \mathrm{C}$ and $5 \% \mathrm{CO}_{2}$. Viruses were observed at 12-h intervals and harvested until cytopathic effects (CPE) were visible.

\section{Preliminary identification of the recombinant virus}

Specific detection primers of BEV (BEV-F/R) and BVDV E0 (E0-F/R) were designed (Table 3) and applied for PCR identification of the recombinant virus with $2 \times$ Taq Master Mix (Dye) kit (Vazyme, Naijing, China). The identified recombinant plasmid was sent to Genewiz (Suzhou, China) for sequencing.

\section{Detection of the recombinant virus by western blot}

The rescued recombinant virus $\mathrm{rBEV}$-E0 was also detected by western blot according to standard procedures. In brief, MDBK cells were infected with the 10th generation recombinant virus and parental virus, and incubated for $12 \mathrm{~h}$. Viral samples were loaded on a $12 \%$ polyacrylamide gel, transferred to nitrocellulose membranes, and then blocked with $5 \%$ skim milk in Trisbuffered saline with Tween 20 for $2 \mathrm{~h}$ at $37^{\circ} \mathrm{C}$. The membranes were then incubated with anti-BJ101-VP1 monoclonal antibody $(\mathrm{mAb}) 4 \mathrm{~B} 2$ and anti-BVDV E0 polyclonal antibody (PcAb, 1:3000; both prepared in our laboratory) at $37^{\circ} \mathrm{C}$ for $1 \mathrm{~h}$ followed by incubation with horseradish peroxidase (HRP)-conjugated goat antimouse antibody (1:4000; Sigma-Aldrich). Detection was performed using an enhanced chemiluminescence kit (Beyotime, Shanghai, China).

\section{Detection of the recombinant marker viruses by indirect immunofluorescence analysis (IFA)}

The rescued recombinant virus rBEV-E0 and parental virus were transfected in MDBK cells in 96-well plates. After $24 \mathrm{~h}$, the cells were fixed with ice-cold anhydrous ethanol at $4{ }^{\circ} \mathrm{C}$ for $30 \mathrm{~min}$, followed by the addition of $0.3 \%$ Triton 100 for $15 \mathrm{~min}$. Anti-BEV VP1 mAb and anti-BVDV E0 PcAb $(1: 1000)$ were added and the cells were further incubated at $37^{\circ} \mathrm{C}$ for $1 \mathrm{~h}$, followed by

Table 3 Specific primers for detection

\begin{tabular}{llc}
\hline Primer name & Primer sequence (5' to 3') $^{\prime}$ & Product size (bp) \\
\hline BEV-F & TTAAAACAGCCTGGGGGTGTACC & 696 \\
BEV-R & TTACACCCCATCCGGTGGGTG & \\
EO-F & AGATGGAATGAGATACAGCTTGG & 901 \\
E0-R & GGAACGACAGTACTCTCGGA & \\
\hline
\end{tabular}


incubation with fluorescein isothiocyanate-conjugated goat anti-mouse secondary antibody (1:500; SigmaAldrich) in the dark. The results were observed under a fluorescence microscope.

\section{Plaque morphology of the recombinant viruses}

MDBK cells in the six-well plate were infected with the 10th generation recombinant virus and parental virus by 10 -fold gradient dilution at $37^{\circ} \mathrm{C}$ for $2 \mathrm{~h}$. After removing the unabsorbed virus, the cells were overlaid with $2 \mathrm{~mL}$ of $1.5 \%$ low-melting agarose containing $2 \% \mathrm{FBS}$ in DMEM and cultured at $37^{\circ} \mathrm{C}$ in $5 \% \mathrm{CO}_{2}$ for $96 \mathrm{~h}$. The plaques of moderate size were selected by staining with $0.1 \mathrm{~g} / \mathrm{L}$ neutral red solution.

\section{Virus propagation dynamics}

The growth curves of the recombinant virus and parental virus in MDBK cells were compared. In brief, the MDBK cells in 96-well plates were infected at a multiplicity of infection of 1 with the 10th-generation rescued virus or parental virus and incubated at $37^{\circ} \mathrm{C}$ in $5 \% \mathrm{CO}_{2}$ for $1 \mathrm{~h}$. After adsorption, the cells were washed with PBS and added to DMEM containing 2\% FBS. Infected cells were harvested at $3,6,12,24,36$, and $48 \mathrm{~h}$ after infection, and then frozen and thawed three times. The 50\% tissue culture infective dose $\left(\mathrm{TCID}_{50}\right)$ of the virus was calculated according to the Reed-Muench method [20] and each sample was run in triplicate for determination.

\section{Determination of the stability of the recombinant virus}

The stability of the rescued recombinant virus was determined by PCR and sequencing. RNA was extracted from MDBK cells infected with the 3rd, 5th, 7th, and 10th generation recombinant viruses. RNA was then reverse-transcribed into cDNA and used as a template for PCR detection with primers (Table 3). The obtained PCR amplification fragment was sequenced to further identify the BVDV E0 gene in the rescued virus.

\section{Immunogenicity of the rescued recombinant virus}

Twenty-four BALB/c female mice (6-8 weeks old; Charles River, Beijing, China) were randomly divided into four groups of six mice each. The test group was intraperitoneally injected with $10^{8} \mathrm{TCID}_{50}$ of rBEV-E0 and the positive control groups were respectively immunized with the same dose of BVDV and BEV. The final group was a blank control group immunized with PBS. The activity of the mice was observed every day, and blood samples were collected before immunization (D0) and at 7-day intervals after immunization.

The blood samples were separated into serum, and indirect enzyme-linked immunoassay (ELISA) was used to detect anti-BEV VP1 and anti-BVDV E0 antibodies in the immunized mice. The 96-well ELISA plates were coated with VP1 and E0 proteins at $100 \mathrm{ng} / \mathrm{mL}$ each and incubated overnight at $4{ }^{\circ} \mathrm{C}$. The wells were blocked with PBS and Tween containing 1\% bovine serum albumin for $2 \mathrm{~h}$ at $37^{\circ} \mathrm{C}$. Serum samples serially diluted two-fold starting at a dilution of 1:500 were added and incubated at $37^{\circ} \mathrm{C}$ for $1 \mathrm{~h}$, followed by the addition of HRPconjugated goat anti-mouse secondary antibody. Finally, $3,3^{\prime}, 5,5^{\prime}$-Tetramethylbenzidine (TMB) was added for color development, and the reaction was terminated by the addition of $2 \mathrm{~mol} / \mathrm{L} \mathrm{H}_{2} \mathrm{SO}_{4}$. The optical density at $450 \mathrm{~nm}\left(\mathrm{OD}_{450}\right)$ cutoff values were determined for analysis.

\section{Statistical analysis}

Statistical analysis was performed using GraphPad Prism 6 software (GraphPad Software, CA, USA). Data were analyzed using two-way analysis of variance (ANOVA). Data are shown graphically as the geometric mean of the fold change plus the standard error of the mean. A $P$ value of $<0.05$ was considered significant.

\section{Ethical approval}

All animal experimental procedures were approved by the Animal Care and Use Committee of the Institute of Animal Sciences of Chinese Academy of Agricultural Sciences.

\section{Results}

Insertion of BVDV EO in the BEV genome

After generating recombinant infectious BEV-E0 cDNA clones (GpBSK-BEV-E0) following the strategy outlined in Fig. 1, the PCR and sequencing results (Table 3; sequencing results not shown) confirmed that the recombinant infectious clone contained the BVDV E0 gene at the correct position.

\section{Rescue of the recombinant marker viruses}

As shown in Fig. 2, at 24-36 h after transfection of linearized GpBSK-BEV-E0, the BSR-T7 cells showed CPE (mainly manifesting as cell granular lesions, shrinking, rounding and falling off), which were similar to those observed in the cells transfected with the GpBSK-BEV plasmid; however, no CPE was observed in the cells transfected with the empty vector. To confirm that the rescued recombinant virus contained BVDV E0, the sequence across the insertion site of BVDV E0 was amplified by PCR (Fig. 3), and the sequencing results confirmed the existence of BVDV E0.

\section{Expression of BVDV EO in cells infected with recombinant viruses}

Western blots showed a band for VP1 in the MDCK cells infected with both the parental and recombinant viruses (Fig. 4a), whereas the uninfected cells did not 

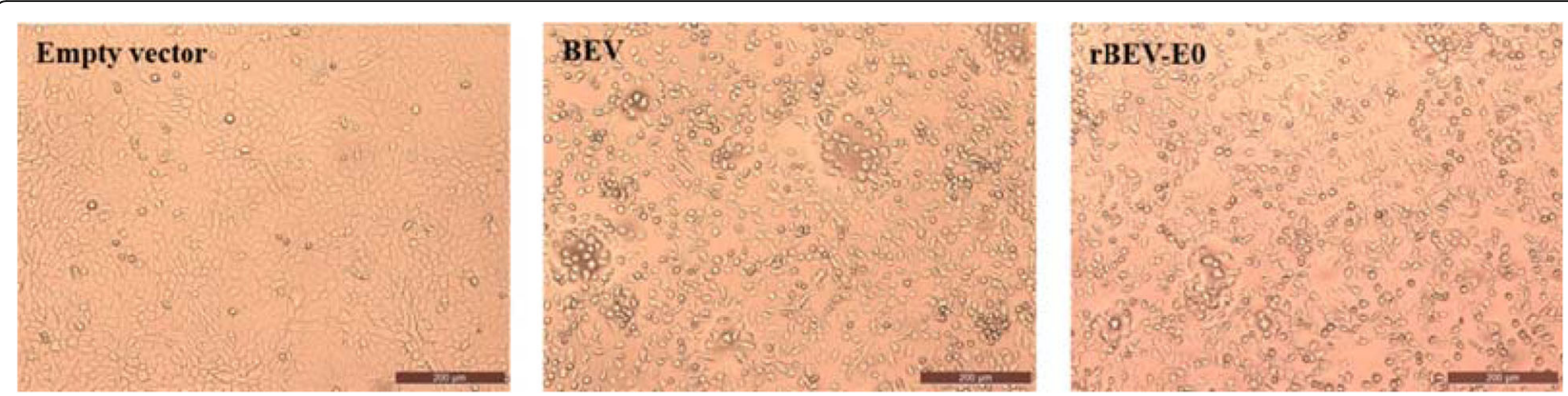

Fig. 2 CPE after infection with rescued recombinant virus. CPE was observed in MDBK cells transfected with linearized GPBSK-BEV-EO plasmid. The parental BEV BJ101 and GpBlueScript (-) empty vector was respectively used as a positive and negative control

produce a band. Using anti-E0 PcAb, only one band appeared in the cell samples infected with the recombinant virus, and no band was observed in the uninfected cells or in the cells infected with the parental virus (Fig. 4b).

Indirect IFA confirmed these results, as the samples infected with recombinant virus or parental virus all reacted with anti-VP1 mAb. The samples infected with the recombinant virus only reacted with anti-EO PcAb, and the uninfected samples did not respond against either anti-VP1 mAb or anti-E0 PcAb (Fig. 5). These results confirmed that the inserted exogenous gene BVDV EO was normally expressed in the cells infected with the recombinant virus.

\section{Plaque morphology}

After infection with the recombinant virus and parental virus for $72 \mathrm{~h}$, obvious CPE was observed in MDBK cells. After staining with neutral red solution, various plaques of different sizes were visible to the naked eye, whereas no plaques appeared in the control group (Fig. 6a). The recombinant virus (Size of plagues: $4.309 \pm 0.4358 \mathrm{~mm}, N=7$ ) showed a plaque morphology similar to that of the parental virus (Size of plagues: $4.495 \pm 0.3649 \mathrm{~mm}, N=4)$, and the difference is not significant ( $p>0.05$, Fig. $6 \mathrm{~b})$.

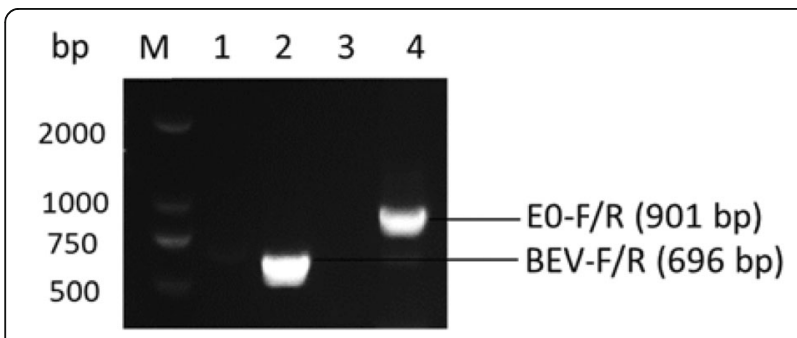

Fig. 3 The PCR identification of rescued recombinant virus. The primer pair BEV-F/R was used in line 1 and line 2 and EO-F/R used in line 3 and line $4 . \mathrm{ddH}_{2} \mathrm{O}$ was used as template for negative control (line 2 and line 4)
Biological characteristics of the recombinant virus

As shown in Fig. 7, the growth characteristics and replication efficiency of the recombinant virus were similar to those of the parental virus, suggesting no effect of the insertion of BVDV E0 at the 2C/3A junction on the biological characteristics of the virus.

\section{Genetic stability of the recombinant viruses}

PCR performed on the 3rd, 5th, 7th, and 10th generations of recombinant viruses showed that the recombinant virus could amplify both the specific detection fragments of BEV and E0 (Fig. 8). All of the recombinant viruses retained the foreign gene BVDV E0 during the passage of MDBK cells, demonstrating the stability of the insertion of BVDV E0 at the 2C/3A junction.

\section{In vivo antibody response to the recombinant viruses}

No obvious clinical signs were observed throughout the observation period, as described in other references. As shown in Fig. 9, at D7 after intraperitoneally injection with recombinant or parental viruses and BVDV, both the rBEV-E0 group and the BEV group produced antiVP1 antibody. The BEV group reached a high antibody level during D14-D21, and the rBEV-E0 group did not reach a corresponding level until D21. In addition, the antibody level in the rBEV-E0 group was lower than that in the BVDV group at the same detection time point, but the difference was not statistically significant. These results showed that mice immunized with $\mathrm{rBEV}$-E0 produced an effective immune response.

\section{Discussion}

Enterovirus is a pathogen that can cause diseases of different degrees, and reverse genetic technology is now widely used to investigate the enterovirus structure and protein function toward the development of viral vector vaccines. Viral vectors are commonly used to deliver genetic material into cells; however, the selection of appropriate viral vectors has long been a major constraint in the development of gene therapy and vector vaccines. 


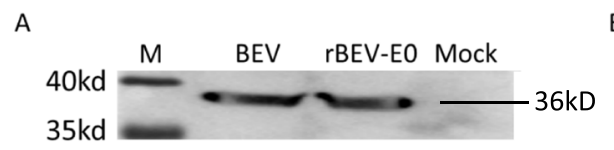

Fig. 4 The Western Blot identification of rescued recombinant virus. Expression of BVDV EO was confirmed with Western blot analysis. MDBK cells infected with parental BEV BJ101 and empty MDBK cells were respectively used as a positive and negative control. Anti-VP1 mAb and anti-E0 PcAb were respectively used in Fig. $4 \mathbf{a}$ and Fig. $4 \mathbf{b}$
An additional challenge is the difficulty in effectively stimulating mucosal immunity using chemically inactivated vaccines. However, $\mathrm{BEV}$, an intestinal pathogen that usually infects animals through the intestines or respiratory tract, is an ideal choice to overcome this problem. BEV is widely distributed in animals, and results in only mild or no clinical symptoms [21]. In addition, BEV has an oncolytic property and can be used as drug therapy [22]. Therefore, BEV is a good candidate to develop a live virus vector for expressing foreign antigens.

In previous study [23], we had obtained the infectious clone of BJ101 strain and successfully rescued the virus. By comparison tests, it was shown that the rescued virus, rBEV had similarity with the parent strain in host tropism, plaque morphology, biological characteristics and genetic stability. This is a preliminary preparation for this research.

The BEV genome contains a large open reading frame encoding four structural proteins and seven nonstructural proteins. Previous studies explored various potential insertion sites for exogenous genes in BEV vectors, including the junction of the VP1 and 2A genes within the $2 \mathrm{~A}, 2 \mathrm{C}, 3 \mathrm{~A}$, and VP1 genes, and in the VP1 B-C or D-E loop [15-17]. Early studies showed no adverse effects on viral biology or replication after insertion of exogenous epitopes at these sites. In this study, we used a reverse genetics platform to explore the feasibility of using BEV as a viral vector to express the BVDV E0 gene, and found a new suitable insertion site (2C/ $3 \mathrm{~A})$. The $2 \mathrm{C}$ protein is highly conserved among enteroviruses, which exhibits ATPase activity and can bind to RNA and the membrane, and has been associated with the virulence of viruses [24]. The 3A protein is derived from a $3 \mathrm{AB}$ precursor protein and is found as an isomeric dimer. In the process of viral infection, $3 \mathrm{~A}$ protein prevents the formation of host proteins and connection with the membrane, and deletion and mutation of a hydrophobic area at the C-terminal of 3A affects replication of the virus [25]. The proteolytic site (ALPQG) at the $2 \mathrm{C} / 3 \mathrm{~A}$ junction is highly conserved in enteroviruses and is recognized by $3 C^{\text {pro }}$. Therefore, in this study, ALPQG was introduced based on primers designed to target both sides of the inserted BVDV E0 gene, so that the original cleavage site between $2 \mathrm{C}$ and $3 \mathrm{~A}$ would not be affected after insertion of the exogenous gene.

Western blot, IFA, and sequencing all confirmed the successful rescue of the recombinant virus. Moreover, the reproductive dynamics and morphological analysis

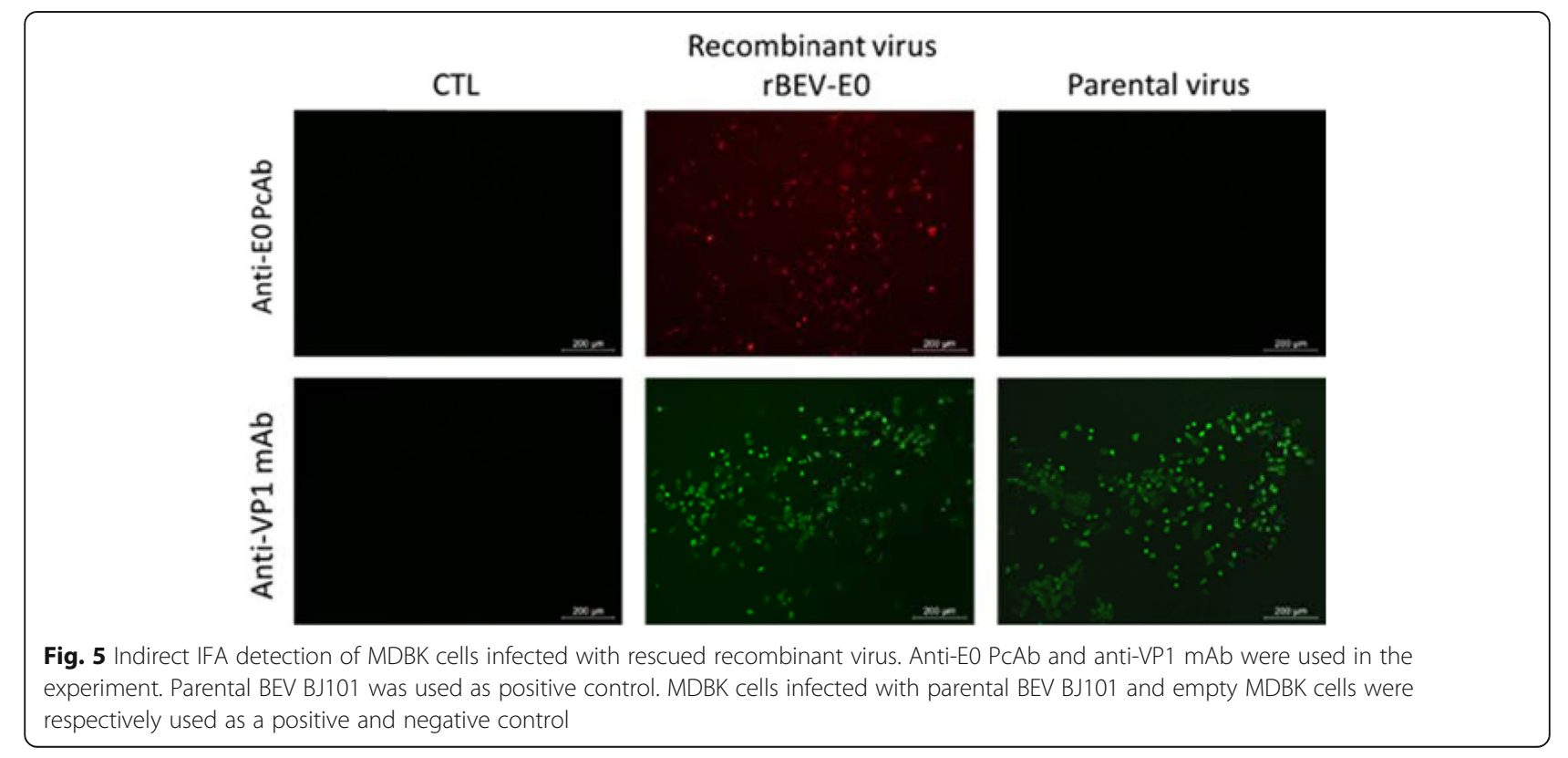




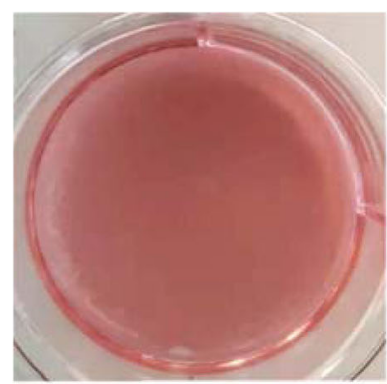

CTL

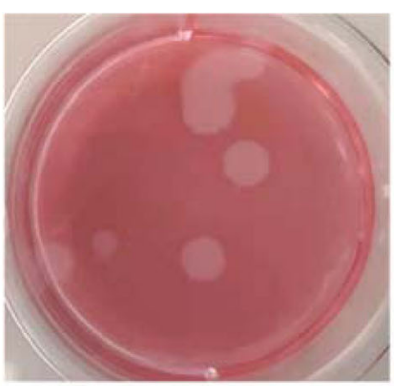

Recombinant virus rBEV-EO

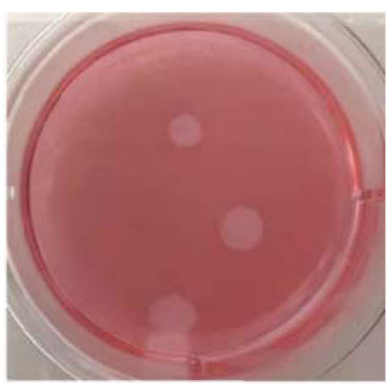

Parental virus

B

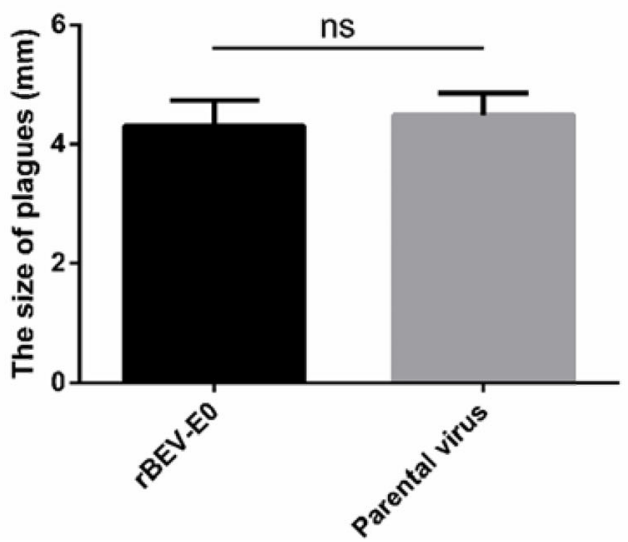

Fig. 6 Morphology of plaques formed by rescued recombinant virus in MDBK cell monolayers. The plaque size and morphology of recombinant virus was not significantly different from that of the parental virus. The representative plaques and variance analysis were respectively displayed in Fig. $6 \mathbf{a}$ and Fig. $6 \mathbf{b}$

showed no influence of the exogenous gene on the replication and morphology of the recombinant virus compared to those of the parental virus. More importantly, the inserted BVDV E0 gene remained stable after 10 passages during viral passage in vitro, suggesting that the $2 \mathrm{C} / 3 \mathrm{~A}$ junction may be an ideal insertion site for

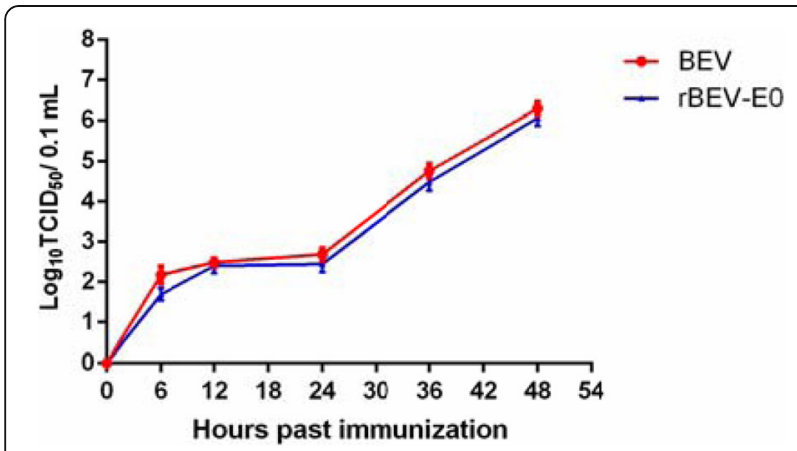

Fig. 7 One-step growth curves of rescued recombinant virus in MDBK cells. MDBK cells were infected with rBEV-EO recombinant viruses and parental BEV, at a $\mathrm{MOI}$ of 1 . The data from three independent experiments are expressed as $\log _{10} \mathrm{TCID}_{50} / 0.1 \mathrm{~mL}$. Error bars represent standard error of the mean (SEM) exogenous genes, antigenic peptides, or markers. In addition to E0 protein, we attempted to insert the HA tag at the $2 \mathrm{C} / 3 \mathrm{~A}$ junction, which also rescued the recombinant labeled virus (data not shown). We also found that the recombinant virus could be rescued using the recognition site for 2A (LTTLG) (data not shown), suggesting that the $2 \mathrm{C} / 3 \mathrm{~A}$ junction in BEV BJ101 is suitable for insertion of an exogenous antigen, and the used hydrolysis sites for $2 \mathrm{~A} / 3 \mathrm{C}^{\text {pro }}$ will not affect the integrity of the $2 \mathrm{C} / 3 \mathrm{~A}$ protein structure or expression of exogenous genes.

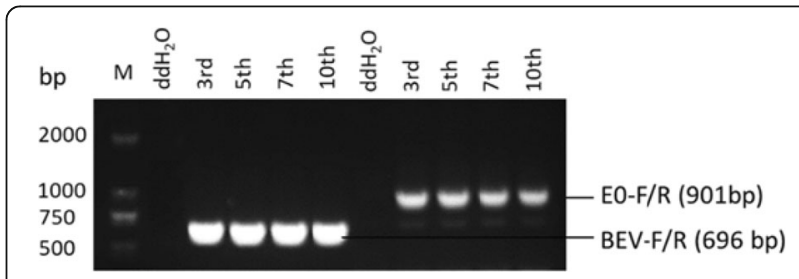

Fig. 8 The genetic stability detection of rescued recombinant virus. PCR with the primer pairs (BEV-F/R and EO-F/R) was performed on the $3 \mathrm{rd}$, 5th, 7th, and 10th generations of recombinant virus $r B E V-E 0$. $\mathrm{ddH}_{2} \mathrm{O}$ was used as template for negative control 
A

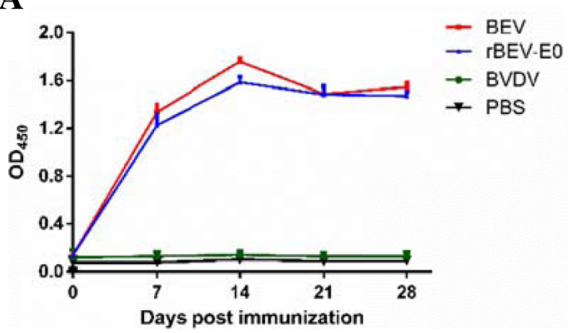

B

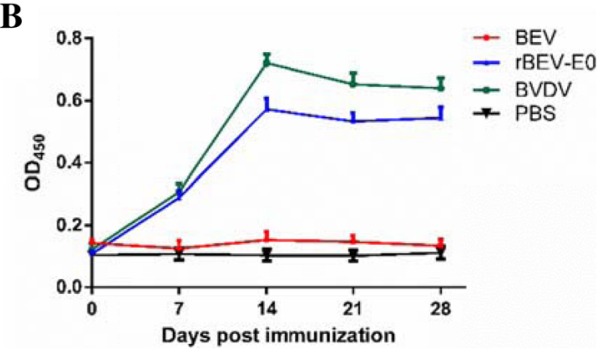

Fig. 9 Antibodies detection in mice infected with rescued recombinant virus. Anti-BEV VP1 and anti-BVDV EO antibodies were detected by ELISA. The sera were collected from mice inoculated with the parental or recombinant marker viruses at 0, 7, 14, 21 and 28 days. (a) BEV-VP1 proteinbased ELISA. (b) BVDV-EO protein-based ELISA. Data are presented as the mean \pm SEM in the same treatment

The prevalence of antibodies against BEV-E was reported to be generally lower than the prevalence of antibodies against BEV-F in cattle populations [26]. Therefore, BJ101, as an EV-E virus, may be more suitable as a live virus vaccine vector than EV-F. In addition, the BEV BJ101 strain used in this study is confirmed to be safe with no report of pathogenesis to our knowledge. Nevertheless, there are two limitations of the use of BEV as a live viral vector [16]. First, the high level of preexisting antibodies to BEV may prevent the vaccine vector from eliciting a strong immune response [27]. In this study, the mice were only infected but did not show any adverse clinical symptoms. We detected both anti-BVDV $\mathrm{E} 0$ and anti-BEV VP1 antibodies in BALB/c mice vaccinated with viruses. Mice vaccinated with the parental virus produced only antibodies against BEV VP1, whereas mice vaccinated with the recombinant virus rBEV-E0 produced antibodies against both VP1 and E0 with high titers. Second, like other picornaviruses, the virion has limited space but is small enough to accommodate exogenous sequences. In previous studies, the possibility of inserting only a few or dozens of amino acids (such as exogenous epitopes and exogenous markers) was explored [28], and the full-length BVDV E0 gene inserted in the present study reached up to 227 amino acids, far exceeding the length of previously inserted sequences. This attempt to insert the maximum virus protective code into the $\mathrm{BEV}$ viral vector can maximize the immunogenicity and offer more complete protection from disease.

\section{Conclusion}

We successfully constructed and rescued the recombinant virus $\mathrm{rBEV}-\mathrm{E} 0$, and demonstrated that insertion of the exogenous gene BVDV E0 at the 2C/3A protein junction did not affect the biological characteristics of the recombinant virus and induced an effective immune response in vivo. This recombinant virus can offer a useful tool for the simultaneous prevention and control of $\mathrm{BEV}$ and BVDV, as well as in further research to find appropriate insertion sites for other exogenous genes or markers. Therefore, rBEVE0 provides an ideal technical platform for the subsequent insertion of exogenous genes, research on the mechanism of action, and further development of viral vector vaccines.

\section{Supplementary information}

Supplementary information accompanies this paper at https://doi.org/10 1186/s12985-020-01338-6.

Additional file 1. The Optimized sequence of BVDV-EO (Length: 681 bp) Additional file 2: Figure S1. GpBlueScript(-) Vector Figure S2 Modified GpBlueScript(-) Vector

Additional file 3: Table S1. The raw data of the anti-BEV VP1 antibodies detection in experimental mice Table S2. The raw data of the anti-BVDV EO antibodies detection in experimental mice

\section{Abbreviations}

ANOVA: Analysis of variance; BEV: Bovine enterovirus; BSA: Bovine serum; BVD: Bovine viral diarrhea; BVDV: Bovine viral diarrhea virus; CPE: Cytopathic effects; DMEM: Dulbecco's modified Eagle's Medium; ELISA: Enzyme-linked immunosorbent assay; FBS: Fetal bovine serum; FITC: Fluorescein isothiocyanate; HA: Hemagglutinin; HRP: Horseradish peroxidase; IFA: Immunofluorescence analysis; mAb: Monoclonal antibody; MDBK: MadinDarby bovine kidney; PBS: Phosphate buffered saline; PBST: Phosphate buffered saline (1\% Tween 20); PCAb: Polyclonal antibody; PCR: Polymerase chain reaction; SEM: Standard error of the mean; $\mathrm{TCID}_{50}$ : Tissue culture infective dose; TMB: 3,3'5,5'-Tetramethylbenzidin

\section{Acknowledgments}

Not applicable.

\section{Authors' contributions}

$X R, S Z, H J$ and $S H$ designed the study; $X R$ and $S Z$ performed the experiments and analyzed the data; $X G, H J, X T, Y J$ and $H Z$ contributed reagents/materials/analysis tools; $X R$ wrote the paper; $S Z, X G, H J$ and $S H$ revised the paper. All authors read and approved the final manuscript.

\section{Funding}

This work was supported by the Fundamental Research Funds for IAS-CAAS (2018-YWF-YTS-17).

\section{Availability of data and materials}

The data used to support the findings of this study are included in this published article. 


\section{Ethics approval and consent to participate}

All animal experimental procedures were approved by the Animal Care and Use Committee at the Institute of Animal Sciences from the Chinese Academy of Agricultural Sciences.

\section{Consent for publication}

Not applicable.

\section{Competing interests}

The authors declare no competing interests.

\section{Author details}

'Institute of Animal Sciences, Chinese Academy of Agricultural Sciences, No. 2. Yuan Ming Yuan West Road Haidian District, Beijing 100193, China. ${ }^{2}$ Biotechnology Research Institute, Chinese Academy of Agricultural Sciences, No. 2, Yuan Ming Yuan West Road Haidian District, Beijing 100193, China.

Received: 6 December 2019 Accepted: 7 May 2020

Published online: 01 July 2020

\section{References}

1. Kunin CM, Minuse E. The isolation in tissue culture, chick embryo and suckling mice of filtrable agents from healthy dairy cattle. J Immunol. 1958; 80:1-11.

2. McFerran JB. ECBO viruses of cattle. Vet Rec. 1958:70:999.

3. Li Y, Chang J, Wang Q, Yu L. Isolation of two Chinese bovine enteroviruses and sequence analysis of their complete genomes. Arch Virol. 2012;157: 2369-75.

4. Blas-Machado U, Saliki JT, Sanchez S, Brown CC, Zhang J, Keys D, Woolums A, Harvey SB. Pathogenesis of a bovine enterovirus-1 isolate in experimentally infected calves. Vet Pathol. 2011;48:1075-84

5. Sobhy NM, Mor SK, Mohammed ME, Bastawecy IM, Fakhry HM, Youssef CR, et al. Isolation and molecular characterization of bovine enteroviruses in Egypt. Vet J. 2015;206:317-21.

6. Ley V, Higgins J, Fayer R. Bovine enteroviruses as indicators of fecal contamination. Appl Environ Microb. 2002;68:3455-61.

7. Jimenez-Clavero MA, Escribano-Romero E, Mansilla C, Gomez N, Cordoba L, Roblas $\mathrm{N}$, et al. Survey of bovine enterovirus in biological and environmental samples by a highly sensitive real-time reverse transcriptionPCR. Appl Environ Microbiol. 2005;71:3536-43.

8. Zheng T. Characterisation of two enteroviruses isolated from Australian brushtail possums (Trichosurus vulpecula) in New Zealand. Arch Virol. 2007; 152:191-8

9. Nollens HH, Rivera R, Palacios G, Wellehan JF, Saliki JT, Caseltine SL, Smith CR, Jensen ED, Hui J, Lipkin WI, Yochem PK, Wells RS, St Leger J, VennWatson S. New recognition of Enterovirus infections in bottlenose dolphins (Tursiops truncatus). Vet Microbiol. 2009:139:170-5.

10. Gur S, Yapkic O, Yilmaz A. Serological survey of bovine enterovirus type 1 in different mammalian species in Turkey. Zoonoses Public Health. 2008:55: 106-11.

11. Beato MS, Marcacci M, Schiavon E, Bertocchi L, Di Domenico M, Peserico A, et al. Identification and genetic characterization of bovine enterovirus by combination of two next generation sequencing platforms. J Virol Methods. 2018;260:21-5

12. Jiang $H$, Weng $L$, Zhang $N$, Arita M, Li R, Chen L, et al. Biochemical characterization of enterovirus 71 3D RNA polymerase. Biochim Biophys Acta. 2011;1809:211-9.

13. Lu GW, Oi JX, Chen Z, Xu X, Gao F, Lin DZ, et al. Enterovirus 71 and Coxsackievirus A16 3C proteases: binding to Rupintrivir and their substrates and anti-hand, foot, and mouth disease virus drug design. J Virol. 2011;85: 10319-31.

14. Mao Q, Wang Y, Bian L, Xu M, Liang Z. EV-A71 vaccine licensure: a first step for multivalent enterovirus vaccine to control HFMD and other severe diseases. Emerg Microbes Infect. 2016;5:e75

15. Chang J, Li Y, Yang D, Wang F, Jiang Z, Yu L. VP1 B-C and D-E loops of bovine enterovirus cluster $B$ can effectively display foot-and-mouth disease virus type O-conserved neutralizing epitope. J Gen Virol. 2013;94:2691-9.

16. Chu JQ, Lee YJ, Park JN, Kim SM, Lee KN, Ko YJ, et al. Construction of a bovine enterovirus-based vector expressing a foot-and-mouth disease virus epitope. J Virol Methods. 2013;189:101-4.
17. Liu D, Liu CM, Liu X, Li X, Huang LP, Hu JY, et al. Rescue and characterization of a recombinant HY12 bovine enterovirus carrying a foreign HA epitope in the 3A nonstructural protein. Arch Virol. 2019;164: 1309-21.

18. Gao Y, Wang S, Du R, Wang Q, Sun C, Wang N, et al. Isolation and identification of a bovine viral diarrhea virus from sika deer in China. Virol J. 2011;8:83.

19. Thomas C, Young NJ, Heaney J, Collins ME, Brownlie J. Evaluation of efficacy of mammalian and baculovirus expressed E2 subunit vaccine candidates to bovine viral diarrhoea virus. Vaccine. 2009;27:2387-93.

20. Malenovska $\mathrm{H}$. Virus quantitation by transmission electron microscopy, $\operatorname{TCID}(5)(0)$, and the role of timing virus harvesting: a case study of three animal viruses. J Virol Methods. 2013:191:136-40.

21. Tsuchiaka S, Rahpaya SS, Otomaru K, Aoki H, Kishimoto M, Naoi Y, Omatsu T, Sano K, Okazaki-Terashima S, Katayama Y, Oba M, Nagai M, Mizutani T. Identification of a novel bovine enterovirus possessing highly divergent amino acid sequences in capsid protein. BMC Microbiol. 2017;17.

22. Sedmak GV, Taylor MW, Mealey J, Chen TT. Oncolytic effect of bovine enterovirus on mouse and human tumours. Nat New Biol. 1972;238:7-9.

23. Zhang S. Construction and Rescue of Bovine Enterovirus Strain BJ101 infectious clone [D]. Hebei: Hebei Agricultural University; 2018.

24. Emerson SU, Huang YK, Nguyen H, Brockington A, Govindarajan S, St Claire $M$, Shapiro M, Purcell RH. Identification of VP1/2A and $2 \mathrm{C}$ as virulence genes of hepatitis a virus and demonstration of genetic instability of 2C. J Virol. 2002;76:8551-9.

25. Gonzalez-Magaldi M, Martin-Acebes MA, Kremer L, Sobrino F. Membrane topology and cellular dynamics of foot-and-mouth disease virus 3A protein. PLoS One. 2014;9(10):e106685.

26. Towner JS, Ho TV, Semler BL. Determinants of membrane association for poliovirus protein 3AB. J Biol Chem. 1996;271:26810-8.

27. Zhang $A Q$, Smith JR, Burgess GW. A capture antibody ELISA for detection of antibodies against bovine enterovirus. J Virol Methods. 1989;24:223-6.

28. Crotty S, Lohman BL, Lu FX, Tang S, Miller CJ, Andino R. Mucosal immunization of cynomolgus macaques with two serotypes of live poliovirus vectors expressing simian immunodeficiency virus antigens: stimulation of humoral, mucosal, and cellular immunity. J Virol. 1999;73: 9485-95.

\section{Publisher's Note}

Springer Nature remains neutral with regard to jurisdictional claims in published maps and institutional affiliations.

Ready to submit your research? Choose BMC and benefit from:

- fast, convenient online submission

- thorough peer review by experienced researchers in your field

- rapid publication on acceptance

- support for research data, including large and complex data types

- gold Open Access which fosters wider collaboration and increased citations

- maximum visibility for your research: over $100 \mathrm{M}$ website views per year

At BMC, research is always in progress.

Learn more biomedcentral.com/submissions 